\title{
The rare reason of left upper quadrant pain: symptomatic cholelitiasis in a situs inversus totalis case
}

\author{
Hasan Çalış, Serdar Şahin, Şerif Melih Karabeyoğlu, Nuraydın Özlem \\ Department of General Surgery, Ahi Evran University Faculty of Medicine, Kırşehir, Turkey
}

\begin{abstract}
Situs inversus totalis is rare embryologic anomaly. The diagnosis is usually made incidentally at some point in life during examination for other diseases. In these cases, it is usually difficult diagnose cholelithiasis during clinical admission as the pain is usually located in the left hypocondrium. Presently described is the case of a patient who was diagnosed symptomatic cholelithiasis with situs inversus totalis.

Keywords: Abdominal pain; cholelithiasis; situs inversus totalis.
\end{abstract}

\section{Introduction}

The case which involves abdominal and thoracic viscera together and also includes dextrocardia is called situs inversus totalis. It is rare embryologic anomaly and an autosomal recessively inherited disorder. The diagnosis is usually made incidentally at a point in life during examinations for other diseases. In such cases, it is usually difficult diagnose cholelithiasis during clinical admission as the pain is usually located in the left hypocondrium. Although laparoscopic cholecystectomy is a standard procedure in cholelithiasis, there could be technical difficulties in the cases of situs inversus totalis. ${ }^{[1]}$ In this paper, we presented a patient who was admitted with left upper quadrant pain and diagnosed symptomatic cholelithiasis with situs inversus totalis.

\section{Case Report}

65 year old female patient admitted to our clinic with left upper quadrant pain that she had for the last 6 months. Abdominal examination and laboratory assessment values were normal. Not knowing the preexisting case of situs inversus totalis of the patient, she was diagnosed with physical examination, posterior-anterior chest radiography and abdominal ultrasound (Figure 1). The abdominal ultrasound revealed multiple $2 \mathrm{~cm}$ gallbladder stones. Laparoscopic cholesystectomy was planned for the patient as there were no pathologies detected. Laparoscopic cholesystectomy was operated using $5 \mathrm{~mm}$ trocars placed on abdominal left upper quadrant. The insertion sites were the same for epigastrium and umbilicus (Figure 2, 3). The patient was discharged post-operative day 1 without any problems. 


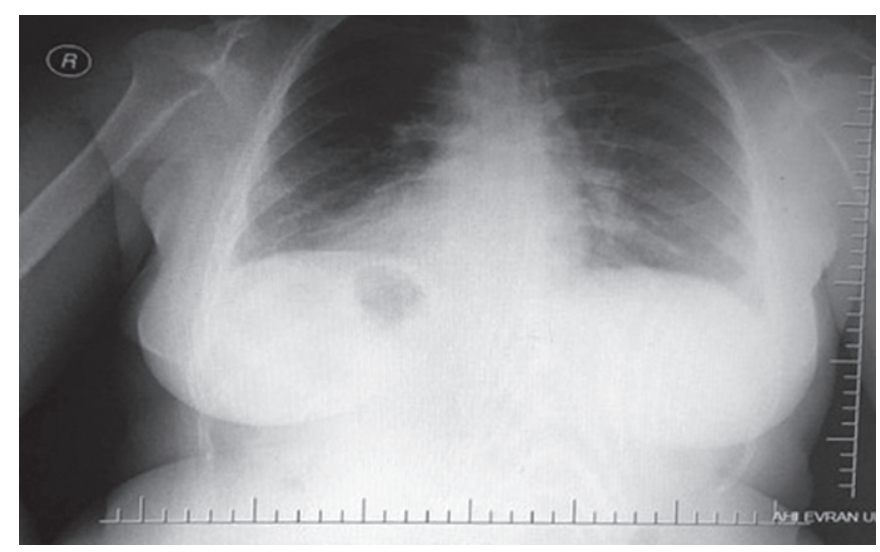

Figure 1. Posterior-Anterior chest radiography: Dextrocardia and gastric fundus gas on the right side of abdomen.

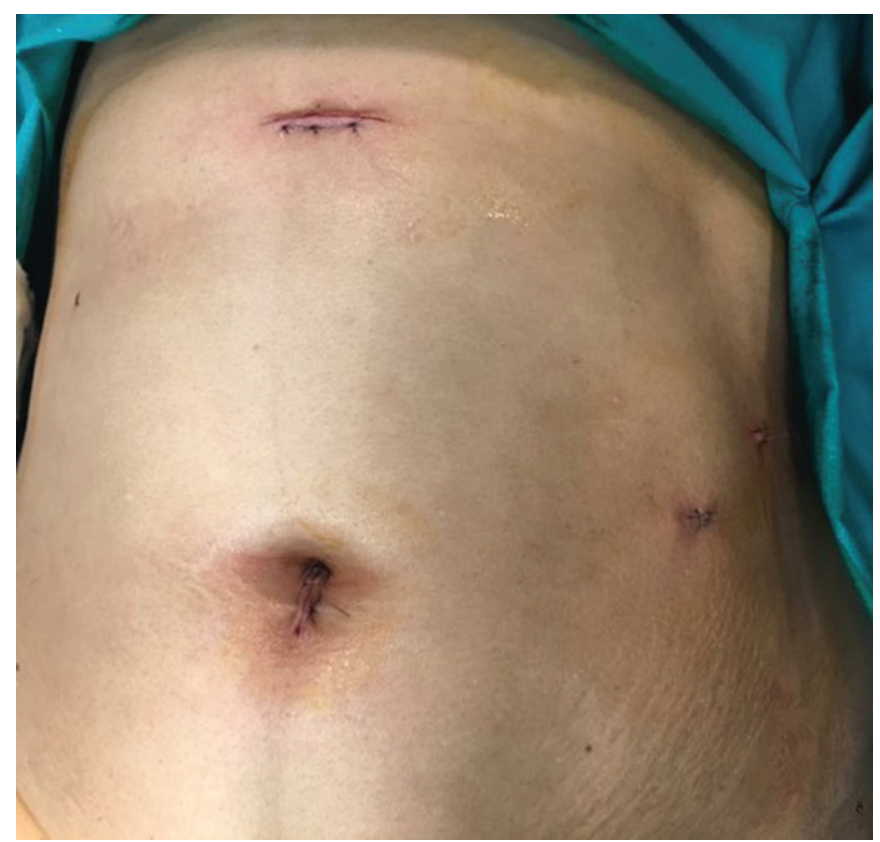

Figure 2. The trocar incisions positioned on the left side of abdomen.

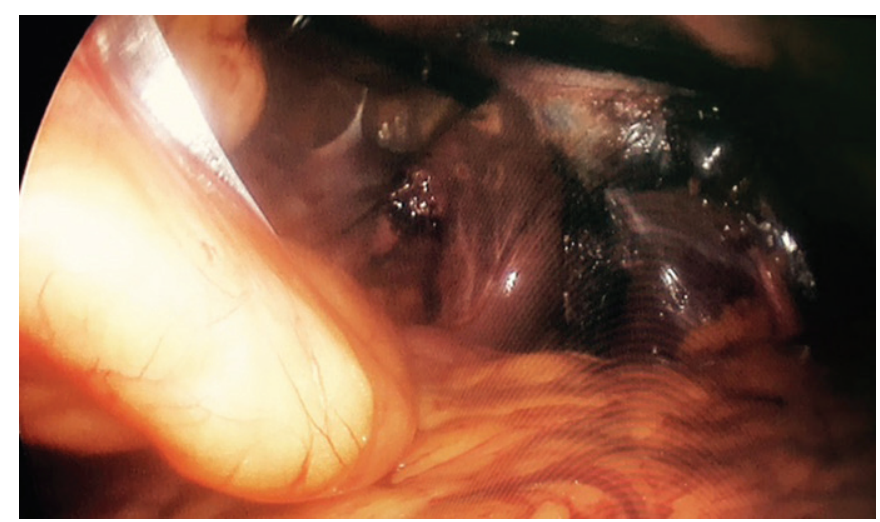

Figure 3. Galbladder presentation during laparoscopic cholecystectomy, observe the falciform ligament on the left side of abdomen.

\section{Discussion}

In situs invertus totalis, thorax and all visceral organs are placed symmetrical to where they should normally be placed. Therefore, pain related to gall bladder pathologies in left upper quadrant could usually be in the left upper quadrant and epigastrium, moreover it could also be felt in the right upper quadrant where it normally takes place. ${ }^{[2]}$ As the diagnosis of situs inversus totalis is usually made by coincidence, symptomatic cholelithiasis should always be remembered as a definitive diagnosis in patients with left hypocondrium and epigastrium pain. It is known that there is no increase in acute cholesystic incidence of patients with situs inversus totalis and extrahapetic biliary, venous and arterial anomalies of these patients are the same as normal population. ${ }^{[3]}$

In gall bladder diseases, laparoscopic cholesystectomy is a golden standard and in situs inversus totalis cases laparoscopic cholesystectomy has no particular complications. Though no increase in the incidence of biliary tract lacerations are reported, it is stated that the duration of the operation could be longer than normal due to orientation. ${ }^{[4]}$

In cases with left hypochondriac pain, situs inversus totalis and symptomatic cholelithiasis are important pathologies to be taken into consideration. In these cases the standard procedure is laparoscopic cholesystectomy and could safely be performed by experienced practitioners.

\section{Disclosures}

Peer-review: Externally peer-reviewed.

Conflict of Interest: None declared.

\section{References}

1. Arya SV, Das A, Singh S, Kalwaniya DS, Sharma A, Thukral BB. Technical difficulties and its remedies in laparoscopic cholecystectomy in situs inversus totalis: A rare case report. Int J Surg Case Rep 2013;4:727-30. [CrossRef]

2. Salama IA, Abdullah MH, Houseni M. Laparoscopic cholecystectomy in situs inversus totalis: Feasibility and review of literature. Int J Surg Case Rep 2013;4:711-5. [CrossRef]

3. Machado NO, Chopra P. Laparoscopic cholecystectomy in a patient with situs inversus totalis: feasibility and technical difficulties. JSLS 2006;10:386-91.

4. Hall TC, Barandiaran J, Perry EP. Laparoscopic cholecystectomy in situs inversus totalis: is it safe? Ann R Coll Surg Engl 2010;92:W30-2. [CrossRef] 